\title{
Masalah dan Optimasi Rapid Sand Filter
}

Oleh Gede H. Cahyana

Lektor Kepala Teknik Lingkungan Universitas Kebangsaan RI

Rapid sand filter sudah dibahas di MAM edisi 312, September 2021. Pembahasan selanjutnya adalah tentang masalah memburuknya kinerja filter dan optimasinya. Filter diharapkan selalu beroperasi optimal agar dapat menghasilkan air yang jernih, dapat membantu proses disinfeksi menjadi efektif dan meminimalkan endapan lumpur yang menyebabkan sumbatan atau pipa pecah di daerah distribusi. Kinerja filter ini dipengaruhi oleh faktor eksternal, yaitu kualitas air yang diolah dan faktor internal filter, yaitu kondisi media filter, media penopang, underdrain, dan parameter backwash, surface wash, air scouring.

Secara alamiah kinerja filter memang menurun setelah beroperasi dalam waktu tertentu. Ini disebabkan oleh media filternya, yaitu akumulasi mikroflok, koloid dan suspended solid di lapisan atas media sehingga mengurangi kapasitas produksi dan kualitas filtratnya memburuk. Penipisan lapisan media pasir akibat bachwashing juga mengurangi kinerja filter. Apabila kondisi filter tidak rutin dipantau tetapi dibiarkan begitu saja beroperasi terus maka suatu saat filter akan rusak, yaitu waktu operasinya (lifetime) sangat singkat dan membutuhkan air pencuci yang banyak tetapi filter tidak bisa pulih ke kinerja optimalnya.

\section{Indikator Kinerja}

Ada beberapa indikator yang perlu diketahui agar filter beroperasi optimal. Yang pertama adalah debit dan yang kedua adalah kekeruhan. Apabila debit air filtratnya berkurang atau kekeruhan air filtratnya lebih tinggi daripada kekeruhan normalnya maka ini pertanda filter mulai tersumbat. Ada sejumlah upaya yang perlu dilakukan pada filter.

Pertama adalah mengamati lapisan pasir sebelum backwash dengan cara membiarkan air meresap ke dalam pasir kemudian amati apakah ada guratan retak (celah), gundukan, atau lubang. Guratan retak menandakan bahwa pencucian filter sebelumnya tidak optimal. Retak terjadi karena endapan menumpuk di antara butir pasir sehingga aliran air menekan pasir ke arah horizontal. Retakan ini menyebabkan air tidak difilter tetapi langsung meresap ke bawah seperti celah bypass.

Adanya gundukan atau lubang di permukaan pasir menandakan bahwa media pasir dalam satu lapisan tipis tidak seragam. Kejadian ini dapat mengakibatkan pertukaran posisi atau dislokasi diameter pasir yang berbeda. Bahkan bisa juga bertukar tempat dengan lapisan kerikil terkecil atau butiran pasir masuk ke sela-sela kerikil. Dampaknya adalah bisa terjadi sumbatan pada underdrain atau bahkan pecah. Aliran air pencuci pun menjadi tidak merata.

Kedua adalah mengamati backwash yang berurutan dengan mencatat prosedur, waktu dan lajunya. Apabila filter dilengkapi dengan fasilitas air scouring atau surface wash maka amati juga turbulensi yang terjadi pada pasir. Turbulensi berlebihan menandakan nozzle-nya pecah. Sedangkan di bagian yang tidak terjadi turbulensi menandakan nozzle-nya tersumbat atau tekanannya kecil. 
Selanjutnya, amati bola kecil lumpur yang terbentuk akibat backwash tidak optimal. Awalnya bola lumpur terbentuk di permukaan pasir tetapi karena makin besar maka tenggelam. Bola lumpur bisa diambil pada waktu filter kosong (tidak beroperasi) atau diambil dengan jaring pada waktu backwashing. Setelah backwash, pasir harus bersih dan rata. Untuk mengetahui apakah backwash optimal, ambillah sedikit sampel pasir, masukkan ke dalam gelas bening dan tutup. Kocoklah yang kuat kemudian biarkan pasir mengendap. Apabila ada lapisan lumpur di bagian atas gelas berarti backwash tidak optimal.

Berikutnya, amati perubahan warna pasir. Pasir filter bisa berubah menjadi hitam apabila air baku banyak berisi kation mangan. Apabila partikulat mangan ini tidak mengakibatkan butiran pasir berlengketan maka tidak akan menimbulkan masalah pada proses filtrasi. Namun dapat bermasalah bagi pelanggan karena dapat mengotori keran, wastafel, alat cuci piring, baju, porselen, keramik, warnanya cepat kusam atau menghitam.

\section{Masalah Utama}

Masalah utama yang terjadi pada rapid sand filter bisa dikelompokkan menjadi empat.

Media filter kotor. Terjadi karena media filter tidak dibersihkan dengan efektif. Backwash tidak mampu membersihkan semua media filter. Ini terjadi karena volume air pencucinya tidak cukup dan/atau distribusi debitnya tidak merata. Maka upayakan backwash lebih lama, lebih merata ke semua area media dan diulang sampai bersih. Tetapi jangan memperbesar kecepatan backwash karena pasir bisa ikut terbuang bersama air cucian.

Endapan lumpur. Setelah periode tertentu maka di permukaan pasir timbul endapan lumpur. Operator bisa melepas endapan dengan cara mengaduk media pasir. Gunakan sekop garpu yang bertangkai panjang sehingga cukup menjangkau media filter di bagian tengah. Tusuktusukan dan geser-geser tongkat bergarpu itu dan semprot dengan air bersih berkecepatan cukup tinggi.

Gumpalan polimer. Ini dipengaruhi oleh kualitas air, khususnya zat organik. Polimer di dalam air bisa menyebabkan pasir berlengketan dan menggumpal seperti dilem sehingga menghambat aliran air selama filtrasi. Ini bisa dibersihkan dengan larutan garam, soda api atau klorin tetapi rumit dan membutuhkan banyak zat kimia. Apabila terjadi di bagian atas saja maka pasir diganti saja dengan yang baru kemudian pasir yang menggumpal ini direndam dengan zat kimia tersebut dan setelah bersih disimpan lagi untuk digunakan pada saatnya nanti.

Underdrain rusak. Underdrain adalah bagian rumit di dalam filter karena lokasinya paling bawah. Kalau terjadi kerusakan di bagian ini maka terpaksa pasir dan kerikil harus digali atau dibongkar. Tetapi upayakan yang dibongkar (digali) hanya terbatas di atas bagian underdrain yang diduga bermasalah. Setelah diperbaiki, pasir dan kerikil dipasang lagi dengan benar. 


\section{Optimasi Filter}

Ada beberapa cara agar filter selalu dalam keadaan berkinerja optimal

Operasi dan perawatan. Filter adalah unit operasi terakhir di dalam IPAM sehingga kinerjanya dipengaruhi oleh unit proses dan operasi sebelumnya. Filter sering bermasalah karena terjadi masalah di proses koagulasi seperti dosis tidak tepat, pengadukan kurang atau flokulasi tidak mampu membentuk flok yang berat. Selanjutnya adalah masalah di sedimentasi, flok tidak bisa mengendap sesuai dengan waktu detensinya. Akibatnya flok tersebut masuk ke filter sehingga menjadi beban berat bagi filter, cepat tersumbat bahkan pasirnya bisa lengket dan menggumpal.

Preventif. Pencegahan lebih baik daripada perbaikan karena rusak. Yang perlu dipantau adalah peralatan backwash dan pengontrol laju aliran. Pompa backwash patut dicek rutin agar dalam kondisi siap operasi. Begitu juga instrumen pengendali laju (kecepatan) aliran airnya.

Kekeruhan. Operator rutin memantau kekeruhan air filtrat. Setiap selesai backwash maka sampel air filtrat segera diambil agar diketahui kekeruhannya. Catat di buku log dan lengkapi dengan data pelengkapnya seperti $\mathrm{pH}$, temperatur, DHL, kondisi cuaca, dll. Kemudian ambil lagi sampel air filtratnya setelah 4 jam filter beroperasi untuk memantau kondisi lapisan pasir dan mengetahui keefektifan backwash.

Jenis koagulan. Flok yang dibentuk oleh koagulan berbasis kation besi lebih melekat dengan pasir daripada flok yang berbasis aluminium. Apabila endapan flok sulit dibersihkan atau dilepaskan dari pasir maka sebaiknya gunakan koagulan alum atau tawas. Tentu dengan pertimbangan bahwa kinerja koagulasi, flokulasi, sedimentasi tidak terganggu dan harganya tidak berbeda jauh.

Filter laju-menurun, declining-rate. Menggunakan filter jenis laju-menurun, yaitu kecepatan filtrasi makin kecil seiring waktu operasinya dapat menghilangkan masalah tekanan negatif dan tidak membutuhkan alat pengendali debit air. Tipe ini lebih mudah dalam operasi dan perawatannya.

Dengan demikian agar kinerja rapid sand filter selalu optimal maka operator hendaklah rutin memeriksa media filter dan mengambil sampelnya, memeriksa sistem perpipaan dan valve, pompa, reservoir air filtrat (wet-well). Juga selalu mengamati proses backwash dan mencatat yang terjadi. Apabila diduga ada masalah segeralah diperiksa, dilaporkan kepada atasan dan ditindaklanjuti. Mencegah kerusakan lebih baik daripada memperbaikinya. [] 


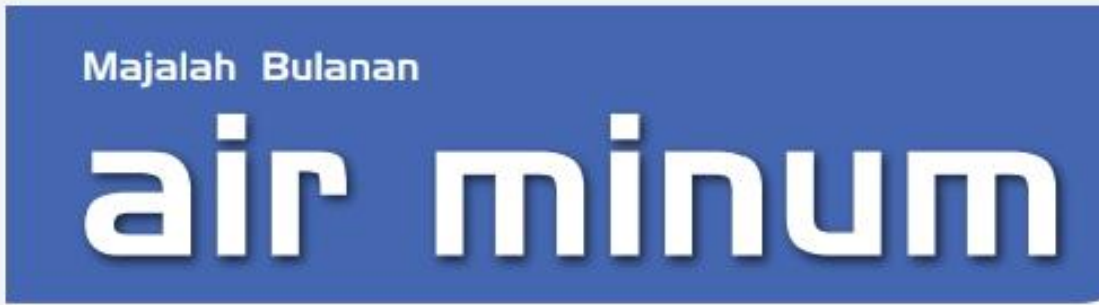

Laporan Utama:

Menakar Untung-Rugi Pembebasan PPN Air
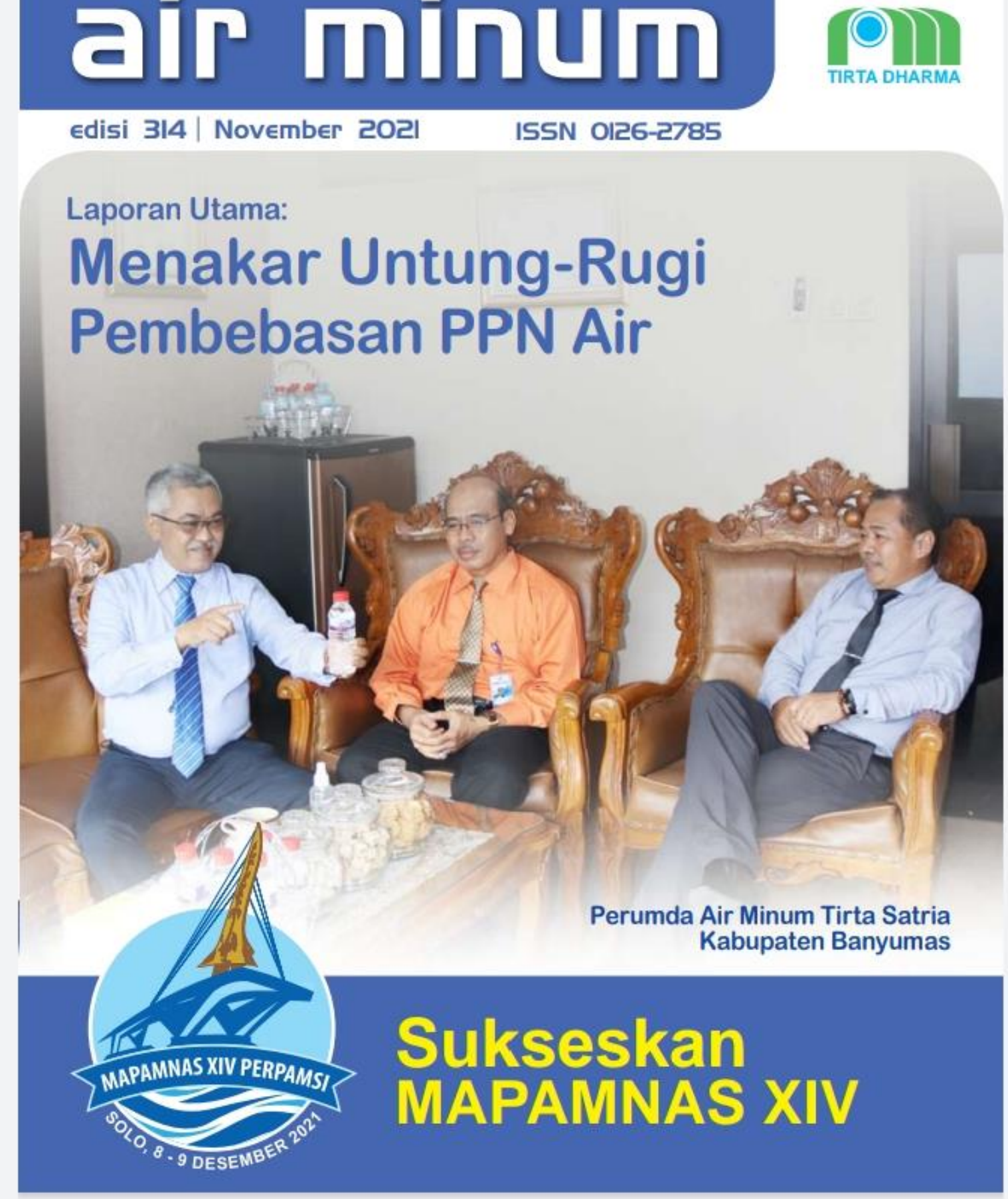


\section{Masalah dan Optimasi Rapid Sand Filter}

Rapid sand filter sudah dibahas di MAM edisi September 2021. Pembahasan selanjutnya adalah masalah memburuknya kinerja filter dan optimasinya. Filter diharapkan selalu beroperasi optimal agar menghasilkan air yang jernih, dapat membantu proses disinfeksi menjadi efektif, dan meminimalkan endapan lumpur yang menyebabkan sumbatan atau pipa pecah di daerah distribusi. Kinerja filter ini dipengaruhi oleh faktor eksternal, yaitu kualitas air yang diolah dan faktor internal filter, yaitu kondisi media filter, media penopang, underdrain, serta parameter backwash, surface wash, dan air scouring.

\section{Qleh: Gede H. Cahyana}

Lektor Kepala Teknik Lingkungan

Universitas Kebangsaan $\mathrm{B}$

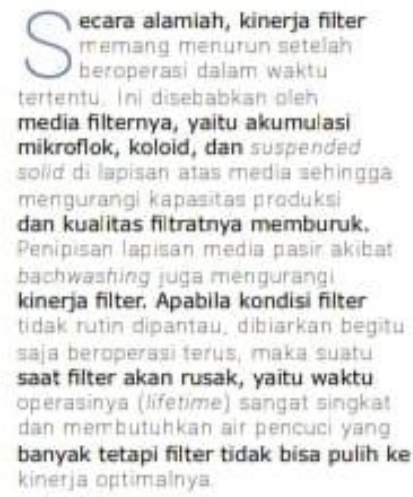

Indikator kinerja

Ada beherapa indikator yang perlu diketahui agar filter beroperasi optimal. Pertama adalah debit dan yang kedua adalah kekeruhan Apabila debit air filtratnya berkurang atau kekeruhan air filtratnya lebih tinggi daripada kekeruhan normainya maka ini pertanda filter mulai tersum tat Ada sejumlah upaya yang perlu dilakukan pada filter.

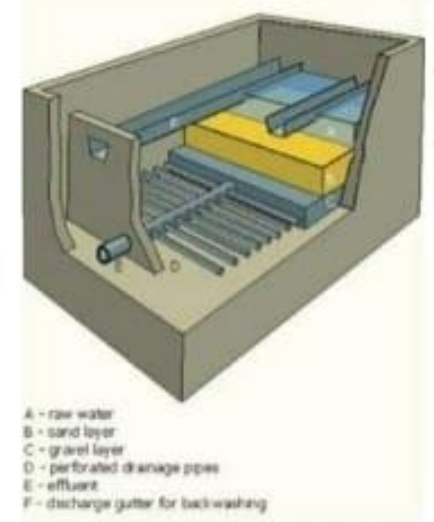

Fertama adalah mengamati lapisan pasir sebelum backwash dengan nara memtiarkan air meresap ke dalan pasir, kertudian arr ati apakah ada guratan retak (celah), gundukan, atar Gaha pencucian filter sebelumnya bahwa pencucian filter sebelumnya

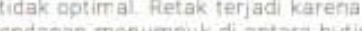
endapan menumpuk di antara buti pasir. Sehingga, aliran air menekan pasir ke araht horizontaj. Retakan in menyebabkan air tidak difilter tetapi langsuing meresap ke bawah sepert ceiah bypass

Adanya gundukan atau lubang di permukaan pasir menandakan tahwa media pasir dalarr satu lapisan tipis

tidak seracam. Kejadian ini dapat mengakibatkan pertukaran posisi atau dislakasi diameter pasit yang bertueda. Bahkan bisa juga bertukar tempat dengan lapisan kerikil terkeci atau butiran pasir masuk ke sela-mala kerikil Dampaknya adalah bisa terjad sumbatan pads underdrain atau bahkan pecah. Aliran air pencuci pun menjadi tidak merata

Kedua adaiah mengamati backwash yang berurutan dengar menoatat frosedur, waktu, dan lajunya. Apabila filter dilengkapi 
dengan fasilitas air scouring atau surface wash, amati juga turbulens yang terjadi pada pasir. Turbulens berlebihan menandakan nozzle-nya pecah. Sedangkan di bagian yang tidak terjadi turbulensi menandakan nozzle nys tersumbat atai

tekanannya kec

Selaniutnya, arrati bola kech lumpur yang terbentuk akibat backwash tidak optimal. Awainya bola lumpur terbentuk di permukaar pasir. Tetapi, karena makin besar. limpur itu tenggelarm Bola lumpur bisa diambil pada waktu filter kosong (tidak beroperasi) atau diambil dengan jaring pada wakty backwashing. Setelah backwash. pasir harus bersih dan fata. Untuk mengetahui apakah backwash optimal, ambil sedikit sampel pasir. masukkan ke dalam gelas bening dar tutup. Kocokiah yang kuat, kemudian biarkan pasir mengendap. Apabila ada topisan lumpur di bagian ata? gelas, berarti backwash tidak optimal

Berikutnya, arrati perubahar wama pasir. Pasir filter bisa berubah menjadi hitart apabila air bakt banyak berisi kation mangan Apabila partikulat mangan in tidak mengakibatkan butiran pasif berlengketan, hal itu tidak akan menimbukar magalah pada proses filtrasi, namun dapat bermasalah bag peianggan karena dapat irengotori keran, wastafel, alat cuci piring, baju. porselen, dan keramik. Warnariya pur cepat kusam atau menghitar

\section{Masalah Utama}

Masalah utarra yang terjadi padi rapid sand filter bisa dikelom pokkan rapid sand fiter
menjadi empat

Media filter kotor. Terjadi karena media filter tidak dibershikan dengan efektif. Backwash tidak mampu membersihkan semua media filter. In terjadi karena volume air pencucinys tidak cukup dan/atau detrbusi debitrya tidak merata. Maka, upayakar backwash lebih lama dan lebiti merata ke semua area media, serta diulang sarr pai bersih. Tetapi, jangar memperbenar kecepatan backwash karena pasir bisa ikut tertuani bersama air cucial

Endapan lumpur. Setelah periode tertentu, di permukaan pasir timbu endapar lumpur Cperator bisa melepas endapan dengan cara mengaduk media pasir Gunakan aekop garpu yang bertangkai panjang sehingga cukup menjangkau media filter di bagian tengah. Tusuk-tusukan dan geser-geser tongkat bergarpu dan semprot dengan air bersih berkecepatan cukup tingg

Gumpalan polimer ini dipengaruhi oleh kualitas air, khusuanya zat

organik. Polimer di dalam air bisa meryebabkan pasir berlengketan dan menggumpal seperti difem, sehingga menghambat aliran air selama filtrasi. ini bisa dibersihkan dengan larutan garart, soda api, atau kiorin, tetap? fumit dan membutuhikan banyak zat kimia. Apabila teriadi hanya do bagian atas ganti saia pasir dengas yang taru Kerrudian, pasir yang menggumpal ini direndam dengan zat kimia tersebut Jika sudah bersin simpan lagi untuk digunakan pada sastrya nanti

Kekeruhan. Operator rutin memantau kekeruhan air filtrat. Setiap selesai backwash, sampel air filtrat segera diambil agar diketahui kekeruhannya.

Underdrain rusak Underdrain adalah bagian rumit di dalam filter karena lokasinya paling trawah. Kalau teriadi kerusakan di bagian in Kalau terjadi kerusakan di bagian in
terpaksa pasir dan kerikil harus digaj terpaksa pasir dan keriki harua digaii
atau dibonokar. Tetapi, upayakan yang atau dibongkar. Tetapi, upayakarn yan dibongkar (digali) hanya terbatas d atas bagian underdrain yang diduga dan kerikil dipasang laci dengan bena

\section{Optimasi Filter}

Berikut beberapa cara agar filter selalu dalam keadaan berkinerja optima

Operasi darn perawatan, Filter adalah unit operasi terakhir d dalam IPAM. Sehingga, kineriany. dipengaruhi oleh unit proses dan operasi rebeliumnya Fitter seting bermanalah katena terad masaiah di proses koagulasi, seperti dosis tidak tepat, pengadukan kurang ata flokulasi tidak mampu membentuk flok yang berat. Selanjutnya adalah masalah di sedimentasi, flok tidak besa mengendap seuvai dengar waktu detensinya. Akibatnya, flok tersebut masuk ke filter, sehingga menjadi beban berat bagi filter, cepat tersumbat, bahkan pagirnya bisa tersumbat, bahkan pasirmy

Preventif. Pencegahan letih baik daripada perbaikan karena ruala Yang perlu dipartau adalah peralatar backwash dan pengontrol tail aliran Pormpu backwash patut dicek tuth agar dalam kondini giap ceerasi Begitu juga instrum en pengendali laji (kecepatan) aliran aieny.

Kekeruhan Operator futir

memantau kekeruhan air filtrat.

Setiap selesai backwash, sampel al filtrat segera diambil agar diketahu kekeruhannya Catat dan lengkapi dengan data pelengkapnya, sepert $\mathrm{pH}$ temperatur. $\mathrm{OHL}$ kondisi cuaca dil. Kemudian, ambil lagi sampel air filtratnya setelah empat jam filter beroperasi untuk memantau kondisi lapisan pasir dan mengetahu keefektifan backwash

Jenis koagulan. Flok yang dibentuk oleh koagulan berbasis kation besi ebih melekat dengan pasir daripada flok yang berbasis aluminium. Apabila endapan flok sulit dibersihkan atau dilepaskan dari pasit, sebaiknys gunakan koagulan alum atai tawas. Tentu dengan pertimbangar bahwa kinerja koagulasi, nokulasi, sedimentasil tidak terganggu dan harganya tidak berbeda jauh

Filter iaju-menurun declining

vate. Menggunakan filter jenis

laju-menurun, yaitu kecepatar filtrasi makin kecil seiring waktu operasinya, dapat menghilangkar masalah tekanan negatif dan tidak membutuhkan aiat pengendali debr ait. Tipe ini lebih mudah dalam operas dan perawatannya

Dengan demikian, agar kinerja rapid sand fitter selalu optimal operator hendaklah rutin memeriksa media filter dan mengambil sarrpelnya, merretikga sistem perpipaan dan vafve, porrpa, dar reservoir air filtrat (wet-weil). Selalu amati juga prones backwash dar catat yang teriadi Apabila diduga ada masalah segeralah diperiksa, laporkan kepado atasan dan tindaklarjuti. Mencegah Kerusakan lebih trai daripada memperbaikinys 